\title{
Improvement of mechanical properties of zirconia-toughened alumina by sinter forging
}

\author{
Y. J. HE, A. J. A. WINNUBST, H. VERWEIJ, A. J. BURGGRAAF \\ University of Twente, Faculty of Chemical Technology, Laboratory for Inorganic Chemistry, \\ Materials Science and Catalysis, P.O. Box 217, 7500AE, Enschede, The Netherlands
}

\begin{abstract}
ZTA powder with a composition of $85 \mathrm{wt} \%$ alumina/15 wt \% zirconia was prepared by a gel precipitation method. Sinter forging was performed with this powder to enhance the mechanical properties of ZTA materials. The influence of processing flaws on mechanical properties of sinter forged materials and pressureless sintered materials was investigated. Sinter forging at $40 \mathrm{MPa}$ effectively decreases process flaw sizes resulting in a homogeneous microstructure and improves the grain boundary structure because of large shear applied in this process. Sinter forging resulted in an increase in strength and toughness by a factor of 1.5-2 when compared with pressureless sintered compacts. The fracture energy is enhanced by a factor of two. The predominate mechanism for improvement of mechanical properties of these sinter-forged ZTA materials is grain boundary strengthening.
\end{abstract}

\section{Introduction}

High wear resistance and good mechanical properties of ceramic materials are required in order to have wide structural applications. Transformation toughening associated with $\mathrm{ZrO}_{2}$-containing ceramics is an effective mechanism for improving the toughness and the strength of a number of brittle ceramics. Zirconiatoughened alumina (ZTA) is one such ceramic. The dispersion of the fine zirconia particles in an alumina matrix enhances fracture toughness of the materials [1-3]. The operating mechanisms are stress-induced martensitic phase transformation from metastable tetragonal zirconia to the monoclinic form [4], microcracking in the matrix around $\mathrm{ZrO}_{2}$ particles which have transformed martensitically [4] or crack deflection around dispersed $\mathrm{ZrO}_{2}$ particles [3]. The strength of ZTA materials, however, is sensitive to the critical flaw size $[5,6]$. An effective method to reduce this flaw size is by reducing the grain size $[7,8]$ and by improving homogeneity of the microstructure [9]. Small grain sizes are associated with corresponding small Griffith's flaw sizes [7]. Krell and Blank [8] have noticed that small grain sizes can hinder the formation of grain-boundary microporosity by relaxation of residual stresses. In such a way, an improvement of grain-boundary structure and a reduction of the subcritical growth of extrinsic flaws result in an enhancement of strength.

Ultrafine powders prepared from chemically homogeneous precursors can be expected to result in better chemical homogeneity of the different constituents and also in great reduction of the sinter temperature. However, it is difficult to obtain non-aggregated or non-agglomerated powders [10]. The remainder of agglomerates in the powder compact after green forming $[5,11-13]$ or different sintering rates in a two- phase ceramic system (e.g. $\mathrm{ZrO}_{2}$ and $\mathrm{Al}_{2} \mathrm{O}_{3}$ ) cause inhomogeneities. Differences in shrinkage rate between separate regions of the powder compacts result in transient stresses [13]. These transient stresses, which act as internal stresses, reduce the sinter pressure [14] and give rise to crack-like pores or some large voids. These flaws are difficult to remove by pressureless sintering. A shear strain of at least $60 \%$ during densification can relax those stresses and eliminates process flaws effectively [11]. The application of advanced pressure-assisted sintering techniques like sinter forging and hot forging $[11,14-16]$ provide the opportunity to prevent the formation of such flaws and improve densification, consequently enhancing the mechanical properties and the reliability of the ceramic materials. Sinter forging is a technique where a uniaxial pressure is applied on specimens, without any lateral constraint. So large shear strains can be present during sintering. Experimental work on ZTA ceramics has shown that sinter forging significantly improved the densification of ZTA compacts at a lower sinter temperature [16].

The mechanical properties of ZTA materials depend on several microstructural parameters such as the amount of tetragonal zirconia which can transform during mechanical loading, zirconia particle location (intergranular or transgranular), grainboundary morphology and the presence of flaws or pores.

In this paper the improvement of microstructure in ZTA ceramics and enhancement of mechanical properties using the sinter forging technique are described and compared to pressureless sintering. The influence is discussed of a shear strain during sinter forging on grain-boundary structure and fracture surface energies. The effect of processing flaws on strength of ZTA 
materials after sinter forging and pressureless sintering are also investigated. The strengthening and toughening mechanisms in these materials are discussed.

\section{Experimental procedure}

\subsection{Sample preparation}

The composition of the powders was $85 \mathrm{wt} \%$ alumina with $15 \mathrm{wt} \%$ (undoped) zirconia. The powders were prepared by the coprecipitation method. In this process a solution of aluminium chloride (Merck, extra pure) and zirconium chloride (Merck, p.a) was hydrolysed in ammonia. The hydrous gel was washed eight times using water/ammonia mixtures in order to remove all the chloride. Subsequently the coprecipitated gel was washed three times with ethanol to remove free water. The filtered gel was dried in air at $120^{\circ} \mathrm{C}$. More experimental details are described elsewhere $[17,18]$. The powders were calcined at 900 or $1100^{\circ} \mathrm{C}$ for $2 \mathrm{~h}$ and dry milled. All powders for producing samples were isostatically cold-pressed at $50 \mathrm{MPa}$. These compacts were ground in an alumina mortar in order to improve the flow behaviour of the powder and subsequently uniaxially pressed in a die into rectangular samples at $50 \mathrm{MPa}$. Finally these samples were isostatically cold-pressed at $400 \mathrm{MPa}$ and pressureless sintered or sinter forged in air. For pressureless sintering the samples were sintered in a Vecstar tube furnace. The heating and cooling rates used were $2{ }^{\circ} \mathrm{Cmin}^{-1}$.

\subsection{Sinter forging}

Sinter forging experiments were carried out in static air using a hot-press equipment with silicon carbide heating elements and $\mathrm{SiC}$ pistons [16-18]. In order to improve the strength of the compacts prior to sinter forging, the green compacts were pre-sintered at $1200^{\circ} \mathrm{C}$ for $15 \mathrm{~min}$, after which the samples were cut into a dimension of $22 \mathrm{~mm} \times 10 \mathrm{~mm} \times 6 \mathrm{~mm}$. During sinter forging, samples were heated to $1150^{\circ} \mathrm{C}$ at a rate of $10^{\circ} \mathrm{Cmin}^{-1}$ with an initial load of $5 \mathrm{MPa}$. The initial pressure was linearly increased to $40 \mathrm{MPa}$ in the temperature range $1150-1200^{\circ} \mathrm{C}$ in $20 \mathrm{~min}$. Finally, the samples were heated to 1400 or $1450^{\circ} \mathrm{C}$ at a rate of $2^{\circ} \mathrm{Cmin}^{-1}$, while the load acting on the sample was held constant. The samples were maintained at the top temperature for $15 \mathrm{~min}$. The experimental pressure was based on the initial dimensions.

The densification and the shear strain (creep strain) are separated using the procedure outlined elsewhere $[16,19]$. The volume strain, $\varepsilon_{\mathrm{v}}$, axial strain, $\varepsilon_{x}, \varepsilon_{y}, \varepsilon_{z}$, and the effective shear strain, $\varepsilon_{e}$, are given by the following relations

$$
\varepsilon_{\mathrm{v}}=\ln \frac{V}{V_{0}}=\ln \frac{\rho_{0}}{\rho}=\varepsilon_{x}+\varepsilon_{y}+\varepsilon_{z}
$$

and

$$
\begin{aligned}
\varepsilon_{x} & =\ln \frac{x}{x_{0}} \\
\varepsilon_{y} & =\ln \frac{y}{y_{0}} \\
\varepsilon_{z} & =\ln \frac{z}{z_{0}}
\end{aligned}
$$

where $x_{0}, y_{0}, z_{0}, V_{0}$ and $\rho_{0}$ are initial length, width, height, volume and density of specimens, respectively, and $x, y, z, V$ and $\rho$ are the values of these parameters after the sinter forging experiment, respectively. The shear strain (creep strain), $\varepsilon_{\mathrm{e}}$, is written as

$$
\varepsilon_{\mathrm{e}}=\frac{2}{3}\left\{\frac{1}{2}\left[\left(\varepsilon_{x}-\varepsilon_{y}\right)^{2}+\left(\varepsilon_{y}-\varepsilon_{z}\right)^{2}+\left(\varepsilon_{z}-\varepsilon_{x}\right)^{2}\right]\right\}^{1 / 2}
$$

\subsection{Characterization}

Specific surface areas of the powders were determined by the BET method using a micromeritics ASAP 2400 system. The densities of green and sintered compacts were measured by the Archimedes' technique, using mercury. The bending strength was measured by the four-point bending technique with an inner and outer span of 10 and $20 \mathrm{~mm}$, respectively, using a crosshead speed of $0.7 \mathrm{~mm} \mathrm{~min}^{-1}$. The samples for measuring bending strength were cut into bars of $26 \mathrm{~mm} \times$ $5 \mathrm{~mm} \times 2 \mathrm{~mm}$ and polished on one side. This side is opposite to the loading piston and endures tensile stress. The polished surface represents the composition and microstructure of the bulk. In order to relieve the effect of surface residual stress produced by cutting and polishing, all specimens before mechanical property measurement were annealed at $1350^{\circ} \mathrm{C}$ using a heating and cooling rate of $2.5^{\circ} \mathrm{C} \mathrm{min}^{-1}$ (dwell time $0 \mathrm{~h}$ ). The fracture toughness was measured by the three-point single-edge notched beam (SENB) technique with a span of $12 \mathrm{~mm}$ using a crosshead speed of $0.3 \mathrm{~mm} \mathrm{~min}^{-1}$. In each sample with dimensions of $15 \mathrm{~mm} \times 3 \mathrm{~mm} \times 1 \mathrm{~mm}$, a notch was cut with a width of $50 \mu \mathrm{m}$ and a depth of $450 \mu \mathrm{m}$; no precracking was performed. After cutting, the samples were annealed in the same way as mentioned above. The fraction of tetragonal to monoclinic transformation caused by mechanical loading was measured on the fracture surface by means of X-ray diffraction analysis using $\mathrm{CuK}_{\alpha}$ radiation in a Phillips PW1710 X-ray diffractometer following the procedure of Toraya [20]. The microstructure of the polished/thermally etched surface and the fracture surface were analysed using a Jeol JSM-35CT scanning electron microscope (SEM). The thermal etching temperature is $25^{\circ} \mathrm{C}$ below the sinter forging temperature for $20 \mathrm{~min}$. The grain sizes of sintered ceramics were measured by the linear intercept method from scanning electron micrographs [21]. The transformation behaviour after sinter forging and pressureless sintering was examined using Jeol 200 CT transmission electron microscope.

\section{Results}

In Table I the density and grain sizes are given after pressureless sintering and sinter forging at 1400 $1500^{\circ} \mathrm{C}$ for $15-120 \mathrm{~min}$. Dense ZTA materials at lower sinter temperatures and shorter dwell times are obtained using sinter forging if compared with pressureless sintering. After sinter forging the zirconia grains are homogeneously dispersed in the alumina matrix, as can be seen in Fig. 1. The influence of calcination temperature on densification of ZTA ceramics 
TABLE I Properties of ZTA ceramics after pressureless sintering and sinter forging

\begin{tabular}{|c|c|c|c|c|c|}
\hline $\begin{array}{l}\text { Sample } \\
\text { code }\end{array}$ & $\begin{array}{l}T_{\text {calc. }} \\
\left({ }^{\circ} \mathrm{C}\right)\end{array}$ & $\begin{array}{l}\text { Sinter } \\
\text { temp./time }\end{array}$ & $\begin{array}{l}\text { Rel. density } \\
(\%)\end{array}$ & $\begin{array}{l}D_{\text {alumina }} \\
(\mu \mathrm{m})\end{array}$ & $\begin{array}{l}D_{\text {zirconia }} \\
(\mu \mathrm{m})\end{array}$ \\
\hline A & 900 & $1500^{\circ} \mathrm{C} / 2 \mathrm{~h}$ & 97 & 1.0 & 0.4 \\
\hline B & 900 & $1400^{\circ} \mathrm{C} / 15 \mathrm{~min} / \mathrm{P}^{\mathrm{a}}$ & 99 & 0.7 & 0.2 \\
\hline $\mathrm{C}$ & 900 & $1450^{\circ} \mathrm{C} / 15 \mathrm{~min} / \mathrm{P}$ & 100 & 0.8 & 0.3 \\
\hline D & 1100 & $1450^{\circ} \mathrm{C} / 2 \mathrm{~h}$ & 98 & 0.8 & 0.3 \\
\hline $\mathbf{E}$ & 1100 & $1500^{\circ} \mathrm{C} / 2 \mathrm{~h}$ & 98 & 1.2 & 0.4 \\
\hline $\mathbf{F}$ & 1100 & $1400^{\circ} \mathrm{C} / 15 \mathrm{~min} / \mathrm{P}$ & 99 & 0.7 & 0.2 \\
\hline $\mathrm{G}$ & 1100 & $1450^{\circ} \mathrm{C} / 15 \mathrm{~min} / \mathrm{P}$ & 100 & 0.8 & 0.3 \\
\hline
\end{tabular}

${ }^{a} P$ is pressure of $40 \mathrm{MPa}$ applied during sinter forging, other samples are pressureless sintered.

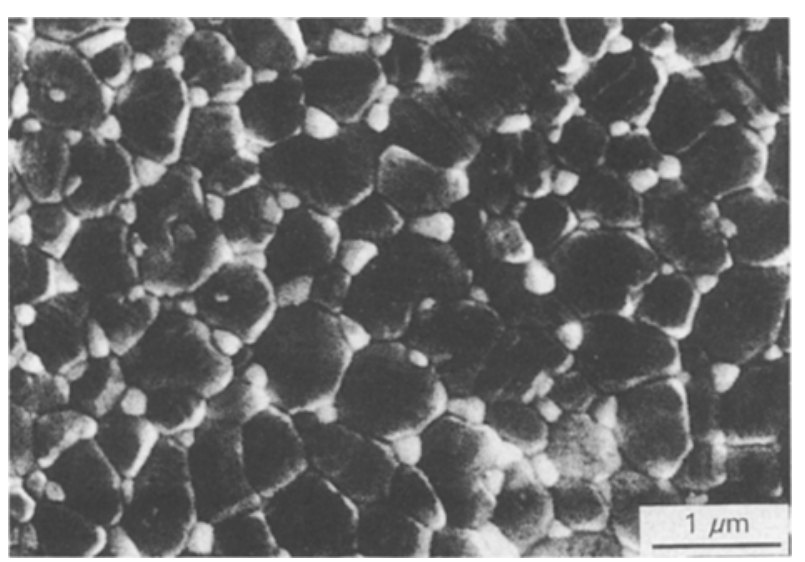

Figure 1 Microstructure of ZTA compacts after sinter forging at $1450^{\circ} \mathrm{C}$ for $15 \mathrm{~min}$. Zirconia particles (slightly light ones) are homogeneously dispersed in the alumina matrix.

under pressureless sinter and sinter forging, as well as the difference in densification behaviour between pressureless sintering and sinter forging, are discussed in detail elsewhere [16-18].

From Table I it can be seen that smaller grain sizes of alumina and zirconia can be obtained for sinterforged ZTA materials when compared with pressureless sintering. After sinter forging at $1400^{\circ} \mathrm{C}$ for $15 \mathrm{~min}$, mean grain sizes of 0.7 and $0.2 \mu \mathrm{m}$ are obtained for alumina and zirconia, respectively. Table I also indicates that the final grain size is only a function of sintering temperature and not of powder calcination temperature.

Compacts of powders which were calcined at $900^{\circ} \mathrm{C}$ do not densify to high density (relative density $>95 \%$ ) after pressureless sintering below $1500^{\circ} \mathrm{C}$. With a calcination temperature of $1100^{\circ} \mathrm{C}$, pressureless sintering for $2 \mathrm{~h}$ at $1450^{\circ} \mathrm{C}$ results in a dense material with alumina and zirconia particle sizes of 0.8 and $0.3 \mu \mathrm{m}$, respectively. Both grain sizes are the same as that after sinter forging at $1450^{\circ} \mathrm{C}$ for $15 \mathrm{~min}$.

The fracture toughness and bending strength of ZTA ceramics after pressureless sintering and sinter forging are given in Table II. From this table, it can be seen that sinter forging strongly affects the mechanical properties. A significantly higher strength and toughness is obtained due to sinter forging for compacts calcined in different ways if compared with pressureless sintering. Strength and fracture toughness after sinter forging is almost independent of calcina-
TABLE II Mechanical properties of the ZTA ceramics after pressureless sintering and sinter forging

\begin{tabular}{|c|c|c|c|c|}
\hline \multirow[t]{2}{*}{$\begin{array}{l}\text { Sample code } \\
\text { (see Table I) }\end{array}$} & \multicolumn{2}{|c|}{$\begin{array}{l}\text { Fraction of } \\
\text { monoclinic } \mathrm{ZrO}_{2}\end{array}$} & \multirow[t]{2}{*}{$\begin{array}{l}K_{\mathrm{IC}} \\
\left(\mathrm{MPa} \mathrm{m}^{1 / 2}\right)\end{array}$} & \multirow[t]{2}{*}{$\begin{array}{l}\sigma_{\mathrm{f}} \\
(\mathrm{MPa})\end{array}$} \\
\hline & $V_{\mathrm{b}}(\%)$ & $\Delta V_{\mathrm{f}}(\%)$ & & \\
\hline A & 24 & 31 & $4.3 \pm 0.3$ & $375 \pm 21$ \\
\hline B & 3 & 24 & $7.3 \pm 0.5$ & $728 \pm 74$ \\
\hline $\mathrm{C}$ & 5 & 28 & $7.4 \pm 0.3$ & $724 \pm 110$ \\
\hline D & 8 & 30 & $5.2 \pm 0.1$ & $380 \pm 90$ \\
\hline $\mathrm{E}$ & 27 & 27 & $4.7 \pm 0.3^{\mathrm{a}}$ & $358 \pm 84^{a}$ \\
\hline $\mathrm{F}$ & 4 & 24 & $7.8 \pm 0.4$ & $610 \pm 100$ \\
\hline G & 6 & 27 & $7.4 \pm 0.4$ & $808 \pm 98$ \\
\hline
\end{tabular}

${ }^{a}$ Values from [18]. $V_{\mathrm{b}}$ is the amount of monoclinic zirconia in the bulk. $\Delta V_{\mathrm{f}}$ is the amount of monoclinic zirconia additionally transformed during fracturing.

tion temperature. For pressureless sintering, compacts sintered at $1500^{\circ} \mathrm{C}$ show a slightly lower fracture toughness than that at $1450^{\circ} \mathrm{C}$, while no difference for bending strength within the standard deviation is obtained. Scanning electron micrographs show that the fracture surface is predominantly intergranular in all cases (see Fig. 2).

It is assumed that the fraction of monoclinic zirconia measured by XRD on polished surfaces represents the real bulk value, $V_{\mathrm{b}}$. The amount of $\mathrm{t}-\mathrm{ZrO}_{2}$ which transformed by mechanical loading is the difference between the fraction of monoclinic zirconia on the fractured surface and on the polished surface $\left(\Delta V_{\mathrm{f}}=V_{\mathrm{f}}-V_{\mathrm{b}}\right)$. The XRD results given in Table II indicate that about $25 \mathrm{vol} \%$ of the zirconia particles are transformed to the monoclinic structure after pressureless sintering at $1500^{\circ} \mathrm{C}$ (samples $\mathrm{A}$ and $\mathrm{E}$ ). In all other cases, the zirconia grains in the bulk are almost $100 \%$ tetragonal. The additional amount of tetragonal zirconia which transforms during fracture, $\Delta V_{\mathrm{f}}$, is almost independent of the temperature treatment (calcination and sintering) and amounts to $25 \%-30 \%$ of the total zirconia volume.

In Fig. 3, the transmission electron micrograph of a pressureless sintered sample at $1500^{\circ} \mathrm{C}$ is given, while Fig. 4 shows the microstructure after sinter forging at $1450^{\circ} \mathrm{C}$. In Fig. 3, a cluster of zirconia particles, which are transformed to the monoclinic structure, can be seen. Such clusters of zirconia particles are often found in samples sintered at $1500^{\circ} \mathrm{C}$. But not all 

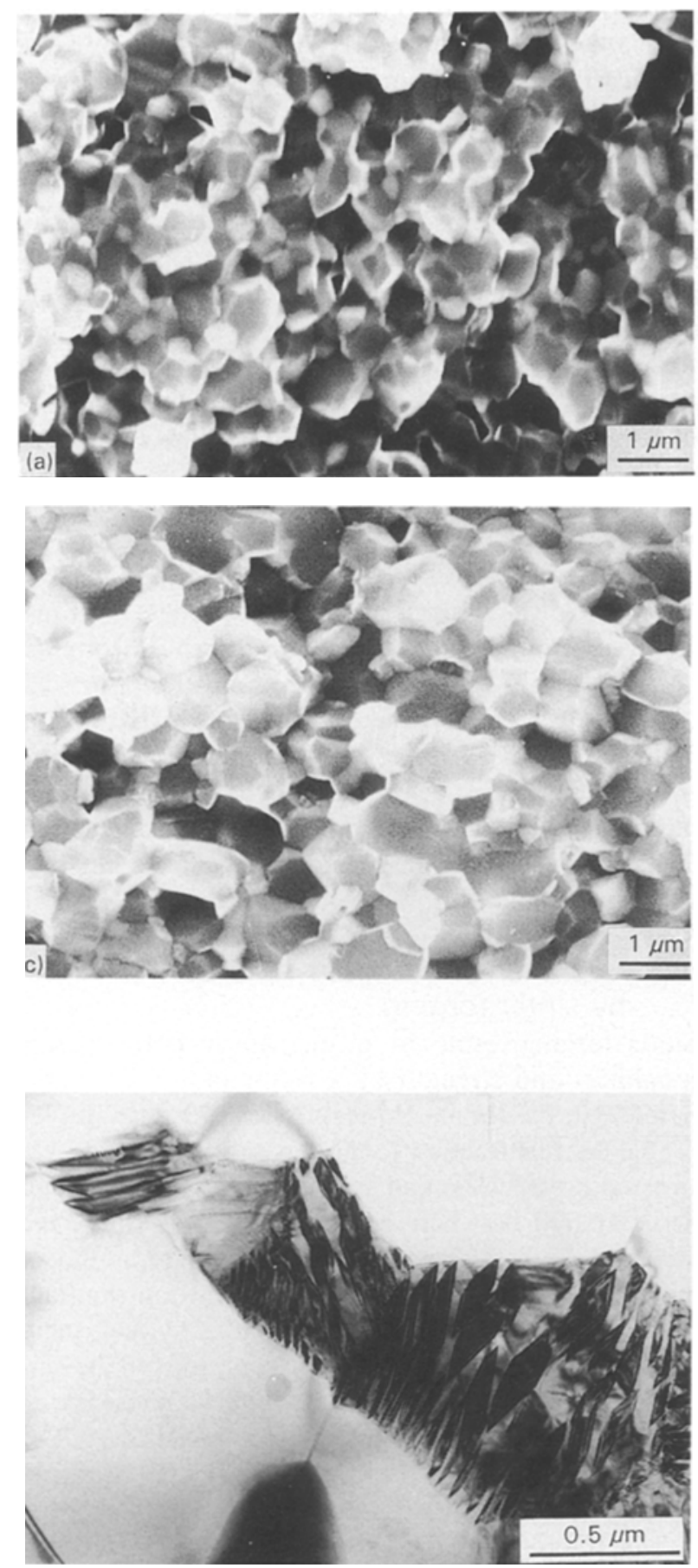

Figure 3 Transmission electron micrograph showing a large zirconia cluster after pressureless sintering at $1500^{\circ} \mathrm{C}$ for $2 \mathrm{~h}$.

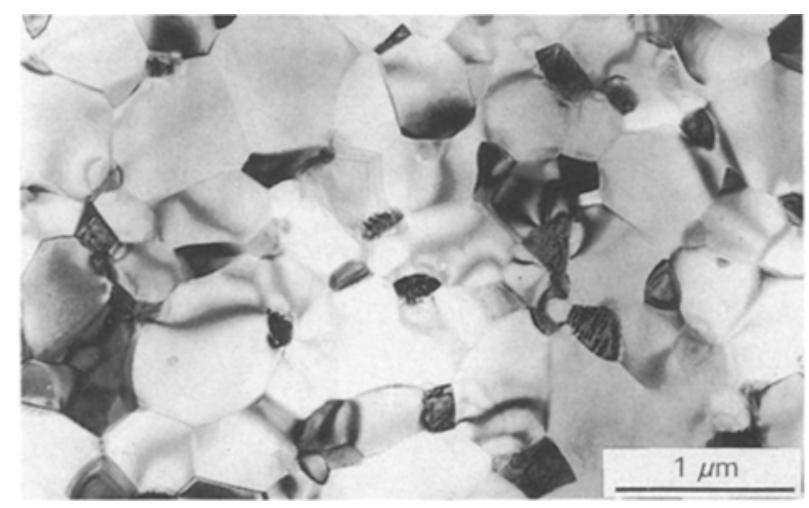

Figure 4 Transmission electron micrograph after sinter forging at $1450^{\circ} \mathrm{C}$ for $15 \mathrm{~min}$

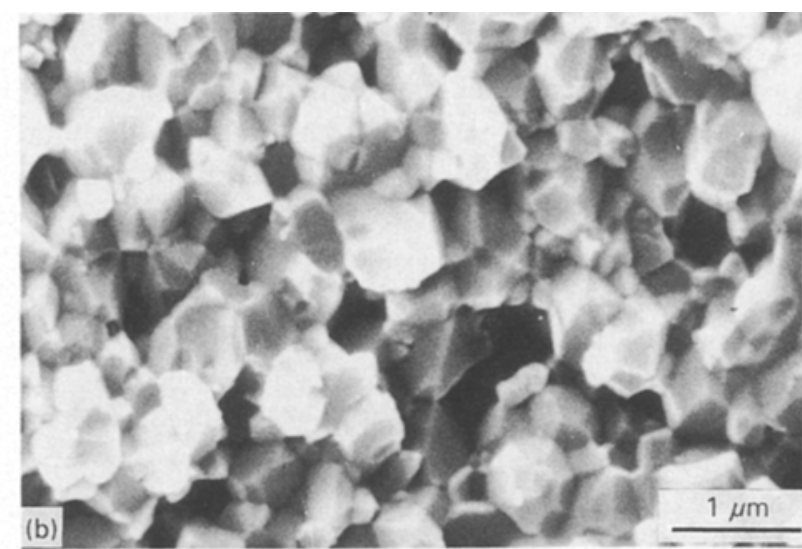

Figure 2 Scanning electron micrograph of the fracture surface of the ZTA ceramic. (a) pressureless sintering, (b) and (c) sinter forging at $1450^{\circ} \mathrm{C}$ for $15 \mathrm{~min}$ after calcining at $900^{\circ} \mathrm{C}$ and $1100^{\circ} \mathrm{C}$ respectively.

zirconia particles are clustered after sintering at this temperature. In Fig. 4 it can be seen that single zirconia particles are well dispersed in the alumina matrix. After sinter forging, for most of the alumina and zirconia grains no significant elongation is observed from Figs 1 and 4. This result is the same as observed by Den Exter [18]. A small degree of the alumina grain elongation, however, was observed in a direction perpendicular to the applied load when zirconia grains are not dispersed completely around the alumina grains [16]. After sinter forging, no detachment of the grain boundaries (boundary cracks) is observed.

\section{Discussion}

\subsection{Mechanical properties after pressureless sintering}

The fraction of monoclinic zirconia, which is transformed by cooling from the sintering temperature or induced by mechanical loading, is dependent on the size of the zirconia grains and generally determines the mechanical properties and the corresponding toughening mechanisms in ZTA materials. For sample $\mathrm{D}$, pressureless sintered at $1450^{\circ} \mathrm{C}, \mathrm{XRD}$ analysis shows that most of the zirconia particles in the bulk are in the metastable tetragonal form while after fracture, $30 \%$ of the zirconia has been transformed. The strength values are rather low, although a certain contribution of stress-induced transformation toughening to the fracture toughness of this material can be observed. After sintering at $1500^{\circ} \mathrm{C}$, much more monoclinic zirconia is present in the bulk after cooling. The reason is that sintering at high temperature (samples A and E) results in grain growth and the formation of some zirconia particle clusters (Fig. 3). Some particles of zirconia are beyond the critical size so that a spontaneous transformation to the monoclinic form occurs during cooling. Den Exter [18] found that for the same composition the critical size of zirconia for the thermally induced transformation is approximately $0.6 \mu \mathrm{m}$. In this situation the mean grain size of the zirconia is about $0.4 \mu \mathrm{m}$, but some particles with a grain size of more than $0.6 \mu \mathrm{m}$ are possible. The spontaneous transformation in these zirconia clusters 
is also caused by the lower constraint pressure around zirconia particles in clusters if compared with individual zirconia particles surrounded by alumina. This effect is due to the larger Young's modulus of alumina. The tensile stress produced by large transformed zirconia particles induces the transformation of smaller zirconia grains which are connected to the larger particles (see Fig. 3). This may result in a value of the critical size smaller than $0.6 \mu \mathrm{m}$ for zirconia in the clusters. Such clusters could not be found in the samples sintered at lower temperature (see Fig. 4). The spontaneous transformation from tetragonal to monoclinic $\mathrm{ZrO}_{2}$ during cooling could not generate microcracking in these ZTA materials. As can be seen from Fig. 3 no microcracks are observed around large monoclinic zirconia clusters. So, in this situation, no microcrack toughening exists. It is possible, however, that microcracks are formed around the large monoclinic particles when an external load is applied (so called stress-induced microcracking).

In the samples sintered at $1500^{\circ} \mathrm{C}$, nearly the same amount of tetragonal zirconia transforms to the monoclinic form during mechanical loading as for the compacts sintered at $1450^{\circ} \mathrm{C}$ (see Table II), while fracture toughness is slightly lower in ZTA samples sintered at $1500^{\circ} \mathrm{C}$. Witek and Butler [3] and Evans [22] pointed out that the $\mathrm{ZrO}_{2}$ particles are retained in the metastable $t$-form but are large enough to produce microcracks after stress-induced transformation. This results in a toughening level smaller than transformation toughening in the absence of microcracks. Probably, the slightly lower fracture toughness for samples sintered at $1500{ }^{\circ} \mathrm{C}$ results from formation of microcracks for relatively larger grain sizes during stressinduced transformation, while this kind of microcrack may not appear for samples with smaller grain sizes sintered at lower temperature.

The bending strength for samples $\mathrm{A}$ and $\mathrm{E}$ sintered at $1500^{\circ} \mathrm{C}$ is expected to be lower than that at $1450^{\circ} \mathrm{C}$ (sample D) due to the presence of microcracks during fracturing in compacts $\mathrm{A}$ and $\mathrm{E}$, and the presence of monoclinic $\mathrm{ZrO}_{2}$ in the composite after cooling, as mentioned elsewhere [23]. The results for compacts sintered at 1500 and $14500^{\circ} \mathrm{C}$, however, are almost same. We also expect that the bending strength in both cases could be increased obviously by stressinduced transformation toughening. For such material with the same chemical composition, Den Exter [18] also found that the bending strength was independent of the fraction of monoclinic zirconia. We suppose that the bending strength is strongly influenced by the presence of flaws. In this case stressinduced transformation for increasing the bending strength is relatively inefficient. This will be discussed below.

\subsection{Effects of stress-induced transformation}

The processing flaws and the residual pores present in the pressureless sintered samples reduce the matrix stiffness. Parts of the compressive stresses induced by transformation are released in the vicinity of the crack front and assisted the extension of the microcrack.
Here the effectiveness of transformation toughening of tetragonal zirconia is reduced as pointed out by Hori [24]. It has been shown in previous work [16] that sinter forging provides a large shear strain on the samples. This large shear strain can eliminate or suppress the process flaws and close the pores during sinter forging to dense ZTA materials, which results in the increase in stiffness of the matrix. Therefore, the effectiveness of transformation toughening is increased in sinter-forged samples. It is argued that, when the same amount of transformable tetragonal zirconia is present, the function of stress-induced transformation on the increase of fracture toughness and bending strength is larger due to a higher matrix constraint that is caused by sinter forging if compared with pressureless sintering. This increase in mechanical constraint is limited by the maximum elastic modulus of the matrix. So the effectiveness of transformation toughening may not be improved so much (a factor of 1.5-2) for the same composition. For such an improvement of the mechanical properties in sinter-forged ZTA materials, there must be an extra strengthening and toughening mechanism besides the increase of effectiveness of transformation toughening. This is related to grain-boundary structure and process flaws and will now be discussed.

\subsection{Improvement of grain-boundary structure by sinter forging}

Sinter forging results in an increase in both fracture toughness and strength by a factor of 1.5-2 if compared with the results of pressureless sintered samples (Table II). The fracture toughness results of compacts sintered pressureless and sinter-forged at $1450^{\circ} \mathrm{C}$ can be compared best here because these materials have identical grain sizes and almost the same amount of monoclinic zirconia in the bulk, $V_{\mathrm{b}}$, and on the fracture surface, $\Delta V_{\mathrm{f}}$. These results indicate that there must be an extra toughening mechanism for the sinter-forged samples besides stress-induced phase transformation and a stronger matrix constraint. The grain-boundary structure will be considered as a first factor.

The fracture energies listed in Table III are calculated using the following equation (which is given for plain stress conditions) [25]

$$
K_{\mathrm{IC}}=\left(2 \gamma_{1} E\right)^{1 / 2}
$$

where $\gamma_{1}$ is the fracture energy and $E$ the elastic modulus.

TABLE III Mechanical properties of the ZTA ceramics after pressureless sintering and sinter forging

\begin{tabular}{lllll}
\hline $\begin{array}{l}\text { Sample code } \\
\text { (see Table I) }\end{array}$ & $\begin{array}{l}\text { Shear strain, } \\
\varepsilon_{\mathrm{e}}\end{array}$ & $\begin{array}{l}\gamma_{1} \\
\left(\mathrm{~J} \mathrm{~m}^{-2}\right)\end{array}$ & $\begin{array}{l}\gamma_{2} \\
\left(\mathrm{~J} \mathrm{~m}^{-2}\right)\end{array}$ & $\begin{array}{l}\text { Griffith's flaw } \\
\text { size }(\mu \mathrm{m})\end{array}$ \\
\hline A & 0 & 25 & 27 & 32 \\
B & 0.79 & 71 & 72 & 25 \\
C & 1.13 & 73 & 73 & 26 \\
D & 0 & 36 & 37 & 47 \\
E & 0 & 29 & 30 & 43 \\
F & 0.80 & 81 & 82 & 28 \\
G & 1.07 & 73 & 73 & 21 \\
\hline
\end{tabular}


The elastic modulus value used in this calculation is $375 \mathrm{GPa}$ [26]. The difference of $E$ in residual porosity between sinter-forged samples $(>99 \%)$ and pressureless-sintered samples $(98 \%)$ is neglected. The fracture energy normalized to the effect of a small amount of porosity is $\gamma_{2}=\gamma_{1} /(1-P)^{2}[27]$, where $P$ is fractional porosity. The fracture energies of sinter-forged samples are about two times larger than those of pressureless-sintered samples (Table III). Only a slight difference in fracture energy is observed for the samples sinter forged at 1400 and $1450^{\circ} \mathrm{C}$.

All samples exhibit intergranular fracture behaviour. So the difference in fracture energy is mainly caused by the difference in grain-boundary properties. After pressureless sintering some process flaws are still present in the bulk (see Figs 5 and 6). These defects are difficult to be removed by this process. Also the formation of an amorphous phase at the grain boundaries cannot be avoided due to the segregation of impurities at grain boundaries. The flaws cause a concentration of stress and result in the formation of cracks and form an origin of catastrophic fracture. The presence of an amorphous phase weakens the grain boundaries and provides preferred low fracture energy paths for crack propagation. This results in lower fracture energies. Krell and Blank [8] introduced a microscopic grain-boundary energy, $\Gamma^{\mathrm{gb}}$, and a microscopic grain-

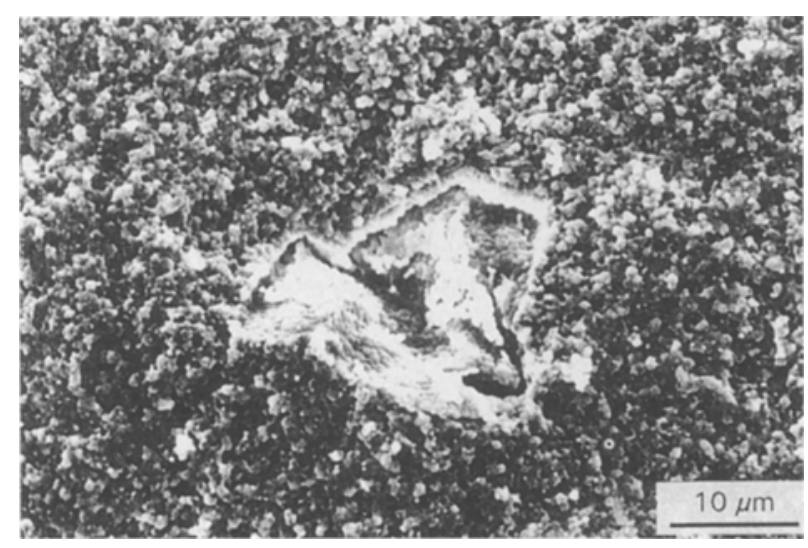

Figure 5 Fracture surface of ZTA after pressureless sintering at $1500^{\circ} \mathrm{C}$ for $2 \mathrm{~h}$. The defect is caused by differential sintering.

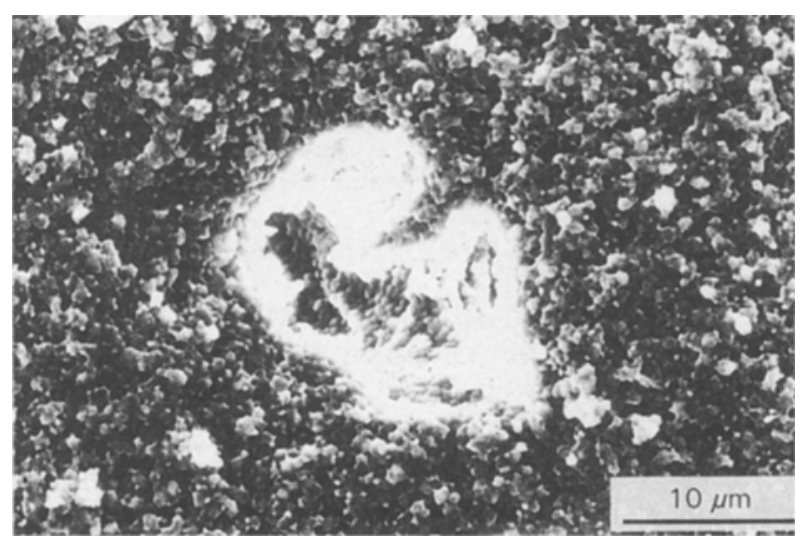

Figure 6 Fracture surface of ZTA after pressureless sintering at $1500^{\circ} \mathrm{C}$ for $2 \mathrm{~h}$. The defect is caused by inhomogeneous packing during green forming. boundary toughness, $K_{\mathrm{IC}}^{\mathrm{gb}}$, in order to understand the mechanism of fracture toughness and strength enhancement by improving grain-boundary structures. They found that an increase of the occurrence of amorphous interfaces and an increase of grain-boundary microporosity are often accompanied by a decrease in the grain-boundary toughness. Sinter forging provides the opportunity to produce large effective shear strains which result in removal of the amorphous film (grain-boundary impurity film) to grain triple junctions. Also, the flaws are removed from the grain boundaries. Partial dewetting of grain boundaries after sinter forging was observed in Y-TZP by Boutz et al. using high-resolution TEM image [15]. So, sinter forging results in an increased fraction of more crystalline and flaw-free grain boundaries and prevents the formation of an amorphous boundary. Grain-boundary structure with improved microscopic $K_{\mathrm{IC}}^{\mathrm{gb}}$ should be able to raise the resistance against subcritical crack growth and then result in the enhancement of the macroscopic toughness.

In conclusion, the toughness of compacts after sinter forging is enhanced principally as a result of the improvement (if present) cannot be neglected also the removal of amorphous phase and flaws. This results in an increase of grain-boundary energy accompanied by an increase of grain-boundary toughness. The increased effectiveness of transformation toughening as a contributing factor in the toughness improvement (if present) also cannot be neglected when the elastic modulus of the matrix is increased by reducing the porosity and process flaws.

\subsection{Decrease of process flaws by sinter forging}

The strength of materials is sensitive to the presence of flaws, which are sources of premature mechanical failure. Normally, such flaws are divided into intrinsic flaws which depend on grain sizes and extrinsic flaws produced by powder processing and sintering [8]. In this work, the strength of ZTA is independent of grain size (see Table II). The influence of intrinsic flaws on the strength of ZTA could therefore be neglected. For these materials, the strength of pressureless-sintered compacts is controlled by extrinsic flaws, which are generated by powder processing and sinter processing. Scanning electron micrographs of the fracture surface in Figs 5 and 6 show the presence of crack-like and large void defects with a size of about $25 \mu \mathrm{m}$ in pressureless-sintered ZTA materials. The formation of these large circumferential (shrinkage) cracks (Fig. 5) is probably caused by different sintering rates due to the presence of the remainders of powder agglomerates. Large voids found in Fig. 6 can be formed from large pores in green compacts. These flaws limit the strength of the pressureless-sintered materials, but is not detected on the fracture surface of sinter-forged samples. Therefore it is important to reduce the finally developed critical size by means of sinter forging, which contributes to an increase of strength.

The critical flaw sizes listed in Table III were calculated using the following modification of the 
Griffith's equation given by Davidge [25]

$$
K_{\text {IC }}=2 \sigma_{\mathrm{f}} a^{1 / 2}
$$

where $K_{\mathrm{IC}}$ is the fracture toughness, $\sigma_{\mathrm{f}}$ is the fracture strength obtained by bending experiment and $a$ is the critical flaw size.

The results in Table III show that critical flaw sizes in the sinter forged samples (samples B, C, F, G) are smaller than those of pressureless sintered samples (samples A, D, E). A flaw size of $25 \mu \mathrm{m}$ for pressureless sintering is observed from SEM, while no flaws are present after sinter forging. So it can be clearly seen that sinter forging decreases or eliminates flaws.

The Griffith's equation shows higher values than the observed SEM values. Probably an extrinsic flaw may link together with some intrinsic flaws such as pores (see Fig. 2a) prior to catastrophic failure [3, 24]. For sinter-forged samples, it is difficult to understand these results (in Table III). Probably cavities due to deformation or residual surface pores which are not polished out completely are linked together to form a large one. It should also be noted that the Griffith's equation is not necessarily valid. High fracture-toughness values may affect the compliance values obtained in Griffith's equation, which is strictly valid only for the pure brittle situation. So the values calculated from the modified Griffith's equation can only be used for comparison.

It is clear that the bending strength of samples after sinter forging is increased by decreasing the critical flaw sizes. This significant enhancement of the bending strength of sinter-forged ZTA materials is achieved by eliminating or suppressing the flaws under large effective shear strain. On the other hand, the fracture paths in sinter-forged ZTA materials are found to be predominantly intergranular (Fig. 2b, c), therefore, it is important that an inherent reinforcement of their microstructure is obtained by sinter forging as mentioned in Section 4.3. Grain-boundary reinforcement by sinter forging should be able to enhance the resistance against subcritical crack growth along the grain boundary, which results in an increased grain-boundary toughness and strength. In the sinter-forged ZTA materials, therefore, the elimination of flaws and the strengthening of grain boundaries are predominant mechanisms in the enhancement of the strength.

\section{Conclusion}

Sinter forging at $1400-1450^{\circ} \mathrm{C}$ with a pressure of $40 \mathrm{MPa}$ resulted in an increase of the bending strength, $\sigma_{\mathrm{f}}$, from $358-380 \mathrm{MPa}$ for pressureless sintering, to $610-808 \mathrm{MPa}$ for sinter-forged materials. Simultaneously the fracture toughness, $K_{\mathrm{IC}}$, increased from 4.3-5.2 $\mathrm{MPa} \mathrm{m}^{1 / 2}$ for pressureless sintered samples to 7.3-7.8 $\mathrm{MPam}^{1 / 2}$ for sinter-forged samples. Sinter-forging provides a shear strain of more than 0.8 was applied.

Grain-boundary fracture energies were doubled to values of $72-82 \mathrm{~J} \mathrm{~m}^{-2}$ for sinter-forged samples.

Large processing flaws (about $25 \mu \mathrm{m}$ ) in pressureless-sintered specimens could be largely eliminated by a shear deformation of $80-100 \%$ and result in an increase in bending strength.
The fracture toughness in ZTA materials mainly depends on stress-induced transformation after pressureless sintering at 1450 and $1500^{\circ} \mathrm{C}$ with zirconia grain sizes of 0.3 and $0.4 \mu \mathrm{m}$, respectively.

It is believed that improvement of the fracture toughness by sinter forging is obtained by an increased toughness of the grain boundaries and by an increased effectivity of the phase-transformation toughening contribution.

\section{Acknowledgements}

Ing. P. M. V. Bakker and Ing. R. J. M. Olde Scholtenhuis are thanked for technical assistance. This research was partly supported by the Innovative Research Programme on Technical Ceramics (IOPTK) with financial aid of the Dutch Ministry of Economic Affairs.

\section{References}

1. N. Claussen, J. Am. Ceram. Soc. 61 (1978) 85.

2. F. F. LANGE, J. Mater. Sci. 17 (1982) 247.

3. S. R. WITEK and E. P. BUT LER, J. Am. Ceram. Soc. 69 (1986) 523.

4. M. RÜHLE, N. CLAUSSEN and A. H. HEUER, ibid. 69 (1986) 195.

5. F. F. LANGE, ibid. 66 (1983) 396.

6. A. G. EVANS, ibid. 65 (1982) 127.

7. J. WANG, M. RAINFORTH and R. STEVENS, Trans. Br. Ceram. Soc. 88 (1989) 1.

8. A. KRELL and P. BLANK, J. Eur. Ceram. Soc. 9 (1992) 309.

9. A. KRELL, P. BLANK and T. WEISS, J. Mater. Sci. 16(1981) 3304.

10. A. J. A. WINNUBST, W. F. M. GROOT ZEVERT, G. S. A. M. THEUNISSEN and A. J. BU R G G R A A F, Mater. Sci. Eng. A109 (1989) 215.

11. K. R, VENKATACHARI and R. RAJ, J. Am. Ceram. Soc. 70 (1987) 514.

12. F. F. LANGE and M. METCALF, ibid. 66 (1983) 398

13. A. G. EVANS, ibid. 65 (1982) 497.

14. K. R. VENKATACHAR and R. RAJ, ibid. 69 (1986) 499.

15. M. M. R. BOUTZ, A. J. A. WINNUBST and A. J. BURGGRAAF, ibid, accepted (1994).

16. Y. J. HE, A. J. A. WINNUBST, H. VERWEIJ and A. J. BURGGRAAF, J. Mater. Sci. accepted (1994).

17. P. DEN EXTER, A. J. A. WINNUBST, T. H. P. LEUWERINK and A. J. BURGGRAAF, J. Am. Ceram. Soc. accepted (1994).

18. P. DEN EXTER, PhD thesis, University of Twente, The Netherlands (1991).

19. R. RAJ, J. Am. Ceram. Soc. 65 (1982) C46.

20. H. TORAYA, M. YOSHIMURA and S. SOMIYA, ibid. 67 (1984) C119.

21. J. C. WURST and J. A. NELSON, ibid. 55 (1972) 109.

22. A. G. EVANS, in "Advances in Ceramics", Vol. 12, "Science and Technology of Zirconia II", edited by N. Claussen, M. Rühle and A. H. Heuer (American Ceramic Society, Columbus, $\mathrm{OH}, 1984)$ pp. 193-212.

23. J. G. P. BINNER, R. S. TOVENS and S. R. TAN, ibid., pp. 428-34.

24. SABUro hori, J. Am. Ceram. Soc. 69 (1986) 169.

25. R. W. DAVIDGE, "Mechanical Behaviour of Ceramics" (Cambridge University Press, Cambridge, UK, 1979).

26. P. F. BECHER, J. Am. Ceram. Soc. 64 (1981) 37.

27. L. A. SIMPSON, ibid. 56 (1973) 7.

Received 12 October 1993

and accepted 16 May 1994 